\title{
ANALISIS MODAL KERJA UNTUK PENINGKATKAN PRODUKTIVITAS PADA PT. UNILEVER INDONESIA, TBK. PERIODE 2006-2010
}

\author{
Engelwati Gani \\ Accounting Department, Faculty of Economic and Communication, BINUS University \\ Jln. K H. Syahdan No. 9, Kemanggisan - Palmerah, Jakarta Barat 11480 \\ engelwatigani@yahoo.com
}

\begin{abstract}
The study was conducted at PT. Unilever Indonesia, Tbk, which aims to determine the level of working capital management and corporate productivity. Quantitative analysis methods used and data analysis techniques used are the working capital analysis, financial ratio analysis and the analysis of the productivity ratio. Research results obtained from the results that a decrease in working capital at PT. Unilever Indonesia, Tbk. from the year 2006-2010 which decreases the amount of current assets while current liabilities increased. PT levels of liquidity. Unilever Indonesia, Tbk. is also quite low and has decreased every year. Expected PT. Unilever Indonesia, Tbk. able to increase the amount of current assets to cash and cash equivalents productivity is not compromised. Productivity ratio of PT. Unilever Indonesia, Tbk in 2010 has increased due to production cost savings and increased sales obtained. This suggests a tight working capital management is carried out by PT. Unilever Indonesia, Tbk. can increase company productivity.
\end{abstract}

Keywords: working capital, productivity, ratio analysis

\begin{abstract}
ABSTRAK
Penelitian dilakukan pada PT. Unilever Indonesia, Tbk yang bertujuan untuk mengetahui pengelolaan modal kerja dan tingkat produktivitas perusahaan. Metode yang digunakan analisis kuantitatif dan teknik analisis data yang digunakan adalah analisis modal kerja, analisis rasio keuangan dan analisis rasio produktivitas. Dari hasil penelitian di peroleh hasil bahwa terjadi penurunan modal kerja pada PT. Unilever Indonesia, Tbk dari tahun 2006-2010 dimana jumlah aktiva lancar semakin menurun sedangkan kewajiban lancar semakin meningkat. Tingkat likuiditas PT. Unilever Indonesia, Tbk juga cukup rendah dan mengalami penurunan setiap tahun. Diharapkan PT. Unilever Indonesia, Tbk mampu meningkatkan jumlah aktiva lancar kas dan setara kas agar produktivitas perusahaan tidak terganggu. Rasio produktivitas PT. Unilever Indonesia, Tbk pada tahun 2010 mengalami peningkatan yang disebabkan oleh penghematan biaya produksi dan peningkatan penjualan yang diperoleh. Hal ini menunjukkan pengelolaan modal kerja secara ketat yang dilakukan oleh PT. Unilever Indonesia, Tbk dapat meningkatkan produktivitas perusahaan.
\end{abstract}

Kata kunci: modal kerja, produktivitas, analisis rasio 


\section{PENDAHULUAN}

Produktivitas memiliki kaitan yang erat dengan kinerja perusahaan. Salah satu faktor yang memengaruhi kemajuan dan kemunduran perusahaan adalah produktivitas, karena peningkatan produktivitas berarti meningkatkan kesejahteraan dan mutu perusahaan. Oleh sebab itu, pengukuran produktivitas di suatu perusahaan perlu dilakukan untuk mengetahui tingkat produktivitas yang telah dicapai dan menjadi dasar perencanaan untuk meningkatkan produktivitas pada masa mendatang.

Agar operasional dapat berjalan dengan efektif dan efisien, manajemen harus mengelola modal kerja yang dimiliki oleh perusahaan dengan baik. Modal kerja sangat erat kaitannya dengan aktivitas sehari-hari perusahaan sehingga dapat dinilai kecepatan perputaran agar tidak terjadi krisis dalam membiayai kebutuhan dana jangka pendek. Dengan melakukan analisis terhadap efisiensi pengelolaan modal kerja, maka kita dapat mengetahui bagaimana kebijakan operasional yang diterapkan oleh perusahaan dan menilai apakah penggunaan modal kerja telah dilakukan secara efisien. PT. Unilever Indonesia, Tbk. merupakan perusahaan terbesar untuk produk Home and Personal Care serta Food and Ice Cream di Indonesia. Beberapa produk PT. Unilever Indonesia, Tbk. mencakup merek-merek ternama yang disukai di dunia seperti Pepsodent, Lux, Lifeboy, Dove, Clear, Sunlight, Blue Band, Bango, dan lain-lain. Perusahaan ini telah memiliki 32 merek utama dan dipasarkan melalui jaringan yang melibatkan 370 distributor independen yang menjangkau seluruh Indonesia. Perseroan memiliki enam pabrik di Kawasan Industri Jababeka, Cikarang, Bekasi, dan pabrik di Kawasan Industri Rungkut, Surabaya, dengan kantor pusat yang berlokasi di Jakarta.

\section{METODE}

Karakteristik riset yang dilakukan adalah sebagai berikut: satu, jenis riset adalah kuantitatif. Dua, riset yang digunakan adalah riset deskriptif. Tiga, dimensi waktu riset menggunakan time series. Empat, metode pengumpulan data yang digunakan adalah kontak tidak langsung berupa data arsip laporan tahunan dan data lain pada PT. Unilever Indonesia, Tbk. yang relevan periode 2006-2010 yang tersedia di website perusahaan. Lima, riset dilakukan secara mendalam yang hanya melibatkan satu objek saja (studi kasus). Dan enam, unit analisis adalah satu unit analisis yaitu PT. Unilever Indonesia, Tbk.

\section{HASIL DAN PEMBAHASAN}

\section{Analisis Perputaran dan Kebutuhan Modal Kerja}

Rasio ini menggambarkan seberapa besar efektivitas modal kerja PT. Unilever Indonesia, Tbk. pada tahun 2006-2010 yang disajikan sebagai berikut:

$$
\text { Average Working Capital Turn Over }=\frac{\text { Peniualan bersith }}{\text { Modal kerja rata }- \text { rata }}
$$


Tabel 1 Average Working Capital Turn Over

\begin{tabular}{crrr}
\hline Tahun & Penjualan* & Modal kerja rata-rata* & Perputaran modal kerja \\
\hline \hline 2006 & $11,335,241$ & $2,317,457$ & 4.89 \\
2007 & $12,544,901$ & $2,649,610$ & 4.73 \\
2008 & $15,578,249$ & $2,898,981$ & 5.37 \\
2009 & $18,247,317$ & $3,352,503$ & 5.44 \\
2010 & $19,690,239$ & $3,674,921$ & 5.36 \\
\hline & & & $*$ dalam jutaan rupiah
\end{tabular}

*dalam jutaan rupiah

Perhatikan tabel 1 di atas. Pada tahun 2008 dan 2009 perputaran modal kerja menjadi lebih cepat karena modal kerja yang digunakan lebih sedikit jika dibandingkan dengan kenaikan penjualan yang diperoleh oleh perusahaan. Sedangkan pada tahun 2010 terjadi penurunan perputaran modal kerja menjadi 5,36 kali. Dalam kurun waktu lima tahun terakhir rata-rata perputaran modal kerja PT. Unilever Indonesia, Tbk adalah sebanyak 5,16 kali yang artinya setiap Rp 1,00 modal kerja dapat menghasilkan Rp 5,16 penjualan. Tingkat perputaran modal kerja dibagi atas dua jenis, yaitu:

\section{Perputaran Modal Kerja Bersih (Net Working Capital Turn Over)}

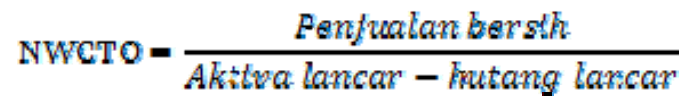

Tabel 2 Net Working Capital Turn Over

\begin{tabular}{crrr}
\hline Tahun & Penjualan* & Modal kerja bersih* $^{*}$ & Perputaran modal kerja \\
\hline \hline 2006 & $11,335,241$ & 547,101 & 20.72 \\
2007 & $12,544,901$ & 266,539 & 47.07 \\
2008 & $15,578,249$ & 12,184 & $1,278.58$ \\
2009 & $18,247,317$ & 12,523 & $1,457.10$ \\
2010 & $19,690,239$ & $(654,810)$ & $(30.07)$ \\
\hline & & & *dalam jutaan rupiah
\end{tabular}

Berdasarkan hasil perhitungan perputaran modal kerja bersih PT. Unilever Indonesia, Tbk. dari tahun 2006 sampai tahun 2010 (Tabel 2) terlihat bahwa perputaran modal kerja bersih mengalami perubahan yang sangat signifikan. Penurunan pada modal kerja bersih yang meningkatkan perputaran modal kerja bersih pada tahun 2010 disebabkan adanya kenaikan penjualan namun tidak diiringi dengan kenaikan kas. Aktiva lancar perusahaan seperti kas menurun dari Rp 858.322.000.000,menjadi Rp 317.759.000.000,-, sedangkan kewajiban lancar seperti hutang usaha justru meningkat. Penurunan aktiva lancar dan peningkatan kewajiban lancar mengakibatkan perputaran modal kerja bersih pada tahun 2010 menjadi tidak terkendali sehingga PT. Unilever Indonesia, Tbk kekurangan modal kerja bersih.

\section{Rasio Modal Kerja Bruto (Gross Working Capital Turn Over)}

$$
\text { GWCTO }=\frac{\text { Penfualan bersth }}{\text { Akttva Lancar }}
$$


Tabel 3 Gross Working Capital Turn Over

\begin{tabular}{rrrr}
\hline Tahun & Penjualan* & Aktiva lancar* & Perputaran modal kerja \\
\hline \hline 2006 & $11,335,241$ & $2,604,552$ & 4.35 \\
2007 & $12,544,901$ & $2,694,667$ & 4.66 \\
2008 & $15,578,249$ & $3,103,295$ & 5.02 \\
2009 & $18,247,317$ & $3,601,711$ & 5.07 \\
2010 & $19,690,239$ & $3,748,130$ & 5.25 \\
\hline & & & *dalam jutaan rupiah
\end{tabular}

Dari hasil perhitungan perputaran modal kerja bruto PT. Unilever Indonesia, Tbk. dari tahun 2006 sampai tahun 2010 (Tabel 3) terlihat bahwa perputaran modal kerja cenderung stabil namun tetap terjadi peningkatan. Semakin cepat perputaran modal kerja bruto yang terjadi, maka semakin kecil modal kerja yang digunakan oleh PT. Unilever Indonesia, Tbk.

\section{Analisis Kebutuhan Modal Kerja}

Analisis dilakukan agar modal kerja dapat ditetapkan secara tepat sehingga tidak mengganggu kegiatan operasional perusahaan. Perhitungan besarnya kebutuhan modal kerja PT. Unilever Indonesia, Tbk. tahun 2006-2010 sebagai berikut:

Pengeluaran kas rata - rata per hard $=\frac{\text { Pentualan }- \text { taba bersth }- \text { deprestast }}{\text { Jumlah hart dalam setahun }}$

Tabel 4 Pengeluaran Kas Rata-rata per Hari

\begin{tabular}{lrrrrr}
\hline \multicolumn{1}{c}{ Keterangan } & \multicolumn{1}{c}{$\mathbf{2 0 0 6}$} & \multicolumn{1}{c}{$\mathbf{2 0 0 7}$} & \multicolumn{1}{c}{$\mathbf{2 0 0 8}$} & \multicolumn{1}{c}{$\mathbf{2 0 0 9}$} & \multicolumn{1}{c}{$\mathbf{2 0 1 0}$} \\
\hline \hline Penjualan & $11,335,241$ & $12,544,901$ & $15,578,249$ & $18,247,317$ & $19,690,239$ \\
Laba bersih & $1,721,595$ & $1,964,652$ & $2,407,231$ & $3,044,107$ & $3,386,970$ \\
Penyusutan aktiva tetap & 61,762 & 82,956 & 88,456 & 135,342 & 148,867 \\
Jumlah hari dalam setahun & 360 & 360 & 360 & 360 & 360 \\
Pengeluaran rata-rata per hari & 26,533 & 29,159 & 36,340 & 41,855 & 44,873 \\
\hline
\end{tabular}

data disajikan dalam jutaan rupiah

$$
\text { Periode terikat }=\frac{\text { Iwmlah hari dalam setahwn }}{\text { Perputaran modal kerja }}
$$

Kebutuhan modal kerja $=$ Pertode tertkat $\times$ pengeluaran kas per hart

Tabel 5 Kebutuhan Modal Kerja

\begin{tabular}{lrrrrr}
\hline \multicolumn{1}{c}{ Keterangan } & $\mathbf{2 0 0 6}$ & $\mathbf{2 0 0 7}$ & $\mathbf{2 0 0 8}$ & $\mathbf{2 0 0 9}$ & $\mathbf{2 0 1 0}$ \\
\hline \hline Jumlah hari dalam setahun & 360 & 360 & 360 & 360 & 360 \\
Perputaran modal kerja & 4.35 & 4.66 & 5.02 & 5.07 & 5.25 \\
Periode terikat & 83 & 77 & 72 & 71 & 69 \\
Kebutuhan modal kerja & $\mathbf{2 , 1 9 5 , 8 3 5}$ & $\mathbf{2 , 2 5 2 , 6 3 8}$ & $\mathbf{2 , 6 0 6 , 0 8 8}$ & $\mathbf{2 , 9 7 1 , 9 6 6}$ & $\mathbf{3 , 0 7 7 , 0 2 9}$ \\
\hline
\end{tabular}


Perputaran modal kerja mengalami peningkatan dari tahun ke tahun yang menyebabkan periode terikat semakin mengecil (perhatikan tabel 5). Meskipun periode terikat menjadi lebih kecil, pengeluaran kas rata-rata per hari PT. Unilever Indonesia, Tbk. yang semakin meningkat menyebabkan kebutuhan modal kerja menjadi ikut mengalami peningkatan.

\section{Analisis Laporan Keuangan}

Analisis yang dilakukan pada PT. Unilever Indonesia, Tbk. terbatas pada laporan rugi-laba dan neraca selama lima tahun, yaitu tahun 2006-2010. Analisis dilakukan menggunakan rasio-rasio keuangan yang terkait dengan modal kerja PT. Unilever Indonesia, Tbk., yaitu: rasio likuiditas, rasio aktivitas, rasio solvabilitas, dan rasio profitabilitas. Selain analisis rasio juga dilakukan analisis siklus konversi kas untuk mengetahui jumlah hari yang diperlukan agar usaha yang dilakukan dapat menghasilkan kas.

\section{Analisis Rasio Likuiditas}

Analisis likuiditas digunakan untuk menganalisis posisi keuangan jangka pendek, yaitu dengan membandingkan komponen yang ada dalam neraca, yaitu total aktiva lancar dengan total kewajiban lancar. Beberapa rasio yang digunakan sebagai analisis likuiditas yaitu:

\section{Rasio Lancar (Current Ratio)}

$$
\text { Current Ratio }=\frac{\text { Akttra lancar }}{\text { Kewaftban tancar }}
$$

Tabel 6 Current Ratio

\begin{tabular}{crrr}
\hline Tahun & Aktiva lancar* Kewajiban lancar* & Current Ratio \\
\hline \hline 2006 & $2,604,552$ & $2,057,451$ & 1.27 \\
2007 & $2,694,667$ & $2,428,128$ & 1.11 \\
2008 & $3,103,295$ & $3,091,111$ & 1.00 \\
2009 & $3,601,711$ & $3,589,188$ & 1.00 \\
2010 & $3,748,130$ & $4,402,940$ & 0.85 \\
\hline \multicolumn{4}{r}{ *dalam jutaan rupiah }
\end{tabular}

Dalam kurun waktu 5 tahun PT. Unilever Indonesia, Tbk. mengalami penurunan rasio lancar sebesar 0,42 kali atau $42 \%$. Hal ini terjadi karena meningkatnya kewajiban lancar yang dimiliki perusahaan. Penurunan rasio lancar menunjukkan penurunan kemampuan perusahaan untuk menjamin kewajiban lancar dengan aktiva lancar yang dimiliki. Pada tahun 2010 PT. Unilever Indonesia, Tbk. dapat dikatakan kurang likuid karena rasio lancar dibawah 100\%, yang artinya aktiva lancar PT. Unilever Indonesia, Tbk. tidak cukup untuk melunasi kewajiban lancar. Perhatikan Tabel 6 di atas.

\section{Rasio Cepat (Acid Test Ratio)}

$$
\text { Acld Test Ratlo }=\frac{\text { Akttra lancar }- \text { Per sedtaan }}{\text { Kewaftban lancar }}
$$


Tabel 7 Acid Test Ratio

\begin{tabular}{rrrrr}
\hline Tahun & Aktiva lancar* & Persediaan* & Kewajiban lancar* & Acid Test Ratio \\
\hline \hline 2006 & $2,604,552$ & 763,398 & $2,057,451$ & 0.89 \\
2007 & $2,694,667$ & 857,563 & $2,428,128$ & 0.76 \\
2008 & $3,103,295$ & $1,284,659$ & $3,091,111$ & 0.59 \\
2009 & $3,601,711$ & $1,340,036$ & $3,589,188$ & 0.63 \\
2010 & $3,748,130$ & $1,574,060$ & $4,402,940$ & 0.49 \\
\hline & & \multicolumn{2}{c}{ *dalam jutaan rupiah }
\end{tabular}

Penurunan rasio cepat pada PT. Unilever Indonesia, Tbk terjadi karena jumlah kas dan setara kas yang terus menurun dari tahun ke tahun. Meskipun piutang usaha juga meningkat, namun tidak meningkatkan jumlah aktiva lancar perusahaan secara signifikan. Selain itu, peningkatan persediaan juga menyebabkan turunnya rasio cepat perusahaan. Pada sisi kewajiban terlihat peningkatan hutang usaha yang menyebabkan besarnya jumlah kewajiban lancar perusahaan.

\section{Rasio Kas (Cash ratio)}

$$
\text { Cash Ratlo }=\frac{\text { Kas }+ \text { Bank }}{\text { Kewaftran lancar }}
$$

Tabel 8 Cash Ratio

\begin{tabular}{crrrr}
\hline Tahun & \multicolumn{1}{c}{ Kas* } & \multicolumn{1}{c}{ Bank $^{*}$} & Kewajiban lancar* & Cash Ratio \\
\hline \hline 2006 & 420 & 423,959 & $2,057,451$ & 0.21 \\
2007 & 519 & 436,705 & $2,428,128$ & 0.18 \\
2008 & 587 & 671,760 & $3,091,111$ & 0.22 \\
2009 & 932 & 369,083 & $3,589,188$ & 0.10 \\
2010 & 822 & 207,937 & $4,402,940$ & 0.05 \\
\hline & & \multicolumn{3}{c}{ *dalam jutaan rupiah }
\end{tabular}

Berdasarkan perhitungan rasio kas di atas (Tabel 8), dapat diketahui bahwa rasio kas PT. Unilever Indonesia, Tbk. dari tahun 2006 sampai 2010 mengalami penurunan. Kecilnya angka rasio kas yang hanya 5\% pada tahun 2010 menunjukan bahwa PT. Unilever Indonesia, Tbk. kurang likuid dan akan kesulitan untuk membiayai hutang jangka pendeknya menggunakan jumlah dana pada kas dan bank.

\section{Analisis Rasio Aktivitas}

Rasio aktivitas merupakan rasio yang digunakan untuk mengukur efektivitas penggunaan aktiva yang dimiliki oleh perusahaan. Penggunaan rasio aktivitas adalah dengan membandingkan tingkat penjualan dengan investasi dalam aktiva untuk satu periode. Beberapa rasio yang digunakan sebagai analisis rasio aktivitas yaitu:

\section{Rasio Perputaran Piutang (Account Receivable Turn Over)}

$$
\text { Account Recelvabls Turn Over }=\frac{\text { Penfualan kredtt }}{\text { Ptutang }}
$$


Tabel 9 Account Receivable Turn Over

\begin{tabular}{crrr}
\hline Tahun & \multicolumn{1}{c}{ Penjualan* } & \multicolumn{1}{c}{ Piutang* } & Receivable Turn Over \\
\hline \hline 2006 & $11,335,241$ & 653,207 & 17.35 \\
2007 & $12,544,901$ & 733,359 & 17.11 \\
2008 & $15,578,249$ & 955,775 & 16.30 \\
2009 & $18,247,317$ & $1,257,921$ & 14.51 \\
2010 & $19,690,239$ & $1,567,538$ & 12.56 \\
\hline & & & *dalam jutaan rupiah
\end{tabular}

Berdasarkan perhitungan yang telah dilakukan, dapat diketahui bahwa perputaran piutang PT. Unilever Indonesia, Tbk. dari tahun 2006 sampai 2010 mengalami penurunan (lihat Tabel 9). Penurunan perputaran piutang disebabkan oleh semakin meningkatnya investasi modal kerja PT. Unilever Indonesia, Tbk. ke dalam piutang dibandingkan kas.

\section{Rasio Rata-rata Penagihan Piutang (Days of Receivable)}

$$
\text { Days of Recelvable }=\frac{\text { Jumlah hart dalam } 1 \text { tahun }}{\text { Perputaran ptutang }}
$$

Tabel 10 Days of Receivable

\begin{tabular}{crrr}
\hline Tahun & Jumlah hari & Perputaran piutang & Days of Receivable \\
\hline \hline 2006 & 360 & 17.35 & 20.75 \\
2007 & 360 & 17.11 & 21.05 \\
2008 & 360 & 16.30 & 22.09 \\
2009 & 360 & 14.51 & 24.82 \\
2010 & 360 & 12.56 & 28.66 \\
\hline
\end{tabular}

Rata-rata penagihan piutang menunjukkan berapa lama hari yang diperlukan untuk melakukan penagihan piutang. Semakin rendah rasio ini maka semakin baik karena piutang dapat ditagih dalam waktu yang lebih singkat. Semakin tinggi rasio ini menunjukkan bahwa perusahaan mengalami kesulitan dalam melakukan penagihan karena waktu yang diperlukan semakin lama. Perhatikan Tabel 10 di atas.

\section{Rasio Perputaran Persediaan (Inventory Turn Over)}

$$
\text { Inventory Turn Over }=\frac{\text { Harga pokok penjualan }}{\text { Persediaan rata }- \text { rata }}
$$

Tabel 11 Inventory Turn Over

\begin{tabular}{rrrr}
\hline Tahun & \multicolumn{1}{c}{ HPP* } & \multicolumn{1}{c}{ Persediaan* } & Inventory Turn Over \\
\hline \hline 2006 & $5,704,438$ & $763,398.00$ & 7.47 \\
2007 & $6,247,189$ & $857,463.00$ & 7.29 \\
2008 & $7,946,674$ & $1,284,659.00$ & 6.19 \\
2009 & $9,205,131$ & $1,340,036.00$ & 6.87 \\
2010 & $9,485,274$ & $1,574,060.00$ & *dalam jutaan rupiah
\end{tabular}

Berdasarkan perhitungan yang telah dilakukan, dapat diketahui bahwa perputaran persediaan PT. Unilever Indonesia, Tbk dari tahun 2006 ke tahun 2010 menurun. Penghitungan rata-rata Perputaran Persediaan (Days of Inventory) adalah sebagai berikut. 


$$
\text { Days of Inventory }=\frac{\text { Iumlah hart dalam } 1 \text { tahun }}{\text { Perputaran persedtaan }}
$$

Tabel 12 Days of Inventory

\begin{tabular}{crrr}
\hline Tahun & Jumlah hari & Perputaran piutang & Days of Inventory \\
\hline \hline 2006 & 360 & 7.47 & 48.18 \\
2007 & 360 & 7.29 & 49.41 \\
2008 & 360 & 6.19 & 58.20 \\
2009 & 360 & 6.87 & 52.41 \\
2010 & 360 & 6.03 & 59.74 \\
\hline
\end{tabular}

Berdasarkan perhitungan rata-rata perputaran persediaan yang dilakukan pada Tabel 12, dapat diketahui bahwa jumlah hari yang diperlukan PT. Unilever Indonesia, Tbk. dalam melakukan perputaran persediaan semakin lama. Peningkatan rata-rata perputaran persediaan disebabkan oleh turunnya rasio perputaran persediaan perusahaan.

\section{Rasio Perputaran Aktiva Tetap (Fixed Asset Turn Over)}

$$
\text { Fiwed Asset Turn Over }=\frac{\text { Penfualan }}{\text { Total aktiva tetap }}
$$

Tabel 13 Fixed Asset Turn Over

\begin{tabular}{rrrr}
\hline Tahun & \multicolumn{1}{c}{ Penjualan* } & Aktiva te tap* & Fixed Asset Turn Over \\
\hline \hline 2006 & $11,335,241$ & $2,021,448$ & 5.61 \\
2007 & $12,544,901$ & $2,638,739$ & 4.75 \\
2008 & $15,578,249$ & $3,401,441$ & 4.58 \\
2009 & $18,247,317$ & $3,883,279$ & 4.70 \\
2010 & $19,690,239$ & $4,953,132$ & 3.98 \\
\hline & & & *dalam jutaan rupiah
\end{tabular}

Berdasarkan perhitungan yang telah dilakukan, dapat diketahui bahwa perputaran aktiva tetap PT. Unilever Indonesia, Tbk dari tahun 2006 sampai tahun 2010 mengalami penurunan.

\section{Rasio Perputaran Total Aktiva (Total Aset Turn Over)}

$$
\text { Tatal Asset Turn Over }=\frac{\text { Panjualam }}{\text { Total } 6 \text { kth } Q}
$$

Tabel 14 Total Asset Turn Over

\begin{tabular}{crrr}
\hline Tahun & \multicolumn{1}{c}{ Penjualan* } & \multicolumn{1}{c}{ Total aktiva* } & Total Asset Turn Over \\
\hline \hline 2006 & $11,335,241$ & $4,626,000$ & 2.45 \\
2007 & $12,544,901$ & $5,333,406$ & 2.35 \\
2008 & $15,578,249$ & $6,504,736$ & 2.39 \\
2009 & $18,247,317$ & $7,484,990$ & 2.44 \\
2010 & $19,690,239$ & $8,701,262$ & 2.26 \\
\hline & & *dalam jutaan rupiah
\end{tabular}

Berdasarkan perhitungan yang telah dilakukan, dapat diketahui bahwa perputaran total aktiva PT. Unilever Indonesia, Tbk. dari tahun 2006 ke tahun 2010 mengalami penurunan walau sempat terjadi peningkatan. Lihat Tabel 14. 


\section{Analisis Rasio Solvabilitas}

Rasio solvabilitas merupakan rasio yang mengukur seberapa besar beban hutang yang ditanggung perusahaan dibandingkan dengan aktiva yang dimiliki. Rasio ini menggambarkan kemampuan perusahaan dalam membayar kewajiban jangka panjangnya apabila perusahaan dilikuidasi. Rasio yang digunakan untuk analisis solvabilitas adalah rasio hutang (Debt to Total Asset).

$$
\text { Debt to Total Asset }=\frac{\text { Tetal kewaftban }}{\text { Total akttra }}
$$

Tabel 15 Debt to Total Asset

\begin{tabular}{crrr}
\hline Tahun & \multicolumn{1}{c}{ Kewajiban* } & \multicolumn{1}{c}{ Aktiva* } & Debt to Total Asset \\
\hline \hline 2006 & $2,249,381$ & $4,626,000$ & $48.6 \%$ \\
2007 & $2,639,287$ & $5,333,406$ & $49.5 \%$ \\
2008 & $3,397,915$ & $6,504,736$ & $52.2 \%$ \\
2009 & $3,776,415$ & $7,484,990$ & $50.5 \%$ \\
2010 & $4,652,409$ & $8,701,262$ & $53.5 \%$ \\
\hline & & \multirow{2}{*}{ *dalam jutaan rupiah }
\end{tabular}

Berdasarkan perhitungan rasio hutang yang telah dilakukan, dapat diketahui bahwa jumlah kewajiban atas aktiva PT. Unilever Indonesia, Tbk. dari tahun 2006 sampai tahun 2010 semakin meningkat. Peningkatan rasio hutang PT. Unilever Indonesia, Tbk disebabkan oleh meningkatnya kewajiban lancar seperti hutang usaha dan hutang lain-lain. Sedangkan pada sisi aktiva khususnya aktiva lancar tidak mengalami banyak peningkatan. PT. Unilever Indonesia, Tbk. harus meningkatkan ekuitas apabila ingin meningkatkan kewajiban. Dengan demikian kewajiban PT. Unilever Indonesia, Tbk. akan mampu dibiayai oleh aset apabila terjadi likuidasi.

\section{Analisis Rasio Profitabilitas}

Rasio profitabilitas merupakan rasio yang digunakan untuk mengukur kemampuan perusahaan dalam mencari keuntungan. Rasio ini juga memberikan ukuran tingkat efektivitas manajemen suatu perusahaan. Hal tersebut ditunjukkan oleh laba yang dihasilkan dari penjualan dan aktivitas investasi. Beberapa rasio yang digunakan sebagai analisis rasio profitabilitas yaitu:

\section{Margin Laba Bersih (Net Profit Margin)}

$$
\text { Net Profit Margin }=\begin{aligned}
& \text { Eaba bergth } \\
& \text { Penfualan }
\end{aligned}
$$

Tabel 16 Net Profit Margin

\begin{tabular}{crrr}
\hline Tahun & Laba Bersih* & \multicolumn{1}{c}{ Penjualan* } & Net Profit Margin \\
\hline \hline 2006 & $1,721,595$ & $11,335,241$ & $15.2 \%$ \\
2007 & $1,964,652$ & $12,544,901$ & $15.7 \%$ \\
2008 & $2,407,231$ & $15,577,811$ & $15.5 \%$ \\
2009 & $3,044,107$ & $18,246,872$ & $16.7 \%$ \\
2010 & $3,386,970$ & $19,690,239$ & $17.2 \%$ \\
\hline & & & *dalam jutaan rupiah
\end{tabular}


Pada Tabel 16, berdasarkan perhitungan yang telah dilakukan, dapat diketahui bahwa margin laba bersih PT. Unilever Indonesia, Tbk. dari tahun 2006 ke tahun 2010 mengalami peningkatan. Peningkatan margin laba bersih PT. Unilever Indonesia, Tbk. disebabkan oleh peningkatan laba bersih yang diperoleh. Peningkatan laba bersih ini terjadi karena PT. Unilever Indonesia, Tbk. mampu menekan biaya produksi sehingga harga pokok penjualan tidak mengalami peningkatan yang berarti. Peningkatan margin laba bersih PT. Unilever Indonesia, Tbk. menunjukkan bahwa manajemen perusahaan mampu menjalankan strategi bisnis yang baik sehingga laba yang diperoleh atas penjualan akan terus meningkat.

\section{Tingkat Pengembalian atas Total Aktiva (Return on Asset/ROA)}

$$
\mathrm{ROA}=\frac{\text { Laba bersth }}{\text { Total akttra }}
$$

Tabel 17 Return on Asset

\begin{tabular}{crrr}
\hline Tahun & \multicolumn{1}{c}{ Laba bersih* } & \multicolumn{1}{c}{ Total aktiva* } & \multicolumn{1}{c}{ Return on Asset } \\
\hline \hline 2006 & $1,721,595$ & $4,626,000$ & $37.2 \%$ \\
2007 & $1,964,652$ & $5,333,406$ & $36.8 \%$ \\
2008 & $2,407,231$ & $6,504,736$ & $37.0 \%$ \\
2009 & $3,044,107$ & $7,484,990$ & $40.7 \%$ \\
2010 & $3,386,970$ & $8,701,262$ & $38.9 \%$ \\
\hline & & & *dalam jutaan rupiah
\end{tabular}

Berdasarkan perhitungan yang telah dilakukan, dapat diketahui bahwa tingkat pengembalian atas total aktiva PT. Unilever Indonesia, Tbk. dari tahun 2006 ke tahun 2010 mengalami peningkatan. Peningkatan ROA yang signifikan pada tahun 2009 disebabkan oleh peningkatan laba bersih dari Rp 2.407.231.000.000 menjadi Rp 3.044.107.000.000. Efisiensi biaya, harga komoditas, dan kurs nilai tukar rupiah yang membaik merupakan faktor utama yang menunjang peningkatan laba tersebut. Sedangkan total aktiva PT. Unilever Indonesia, Tbk. mengalami peningkatan yang konsisten setiap tahun, yakni sekitar Rp 1.000.000.000.000 per tahun. Meningkatnya ROA perusahaan menunjukkan bahwa penggunaan aktiva untuk menghasilkan laba bersih semakin efektif. Lihat Tabel 17.

\section{Tingkat Pengembalian atas Ekuitas (Return on Equity/ROE)}

$$
\text { ROE }=\frac{\text { Eaba bersth }}{\text { Total ekuttas }}
$$

Tabel 18 Return on Equity

\begin{tabular}{crrr}
\hline Tahun & Laba bersih* & Total ekuitas* & Return on Equity \\
\hline \hline 2006 & $1,721,595$ & $2,368,527$ & $72.7 \%$ \\
2007 & $1,964,652$ & $2,692,141$ & $73.0 \%$ \\
2008 & $2,407,231$ & $3,100,312$ & $77.6 \%$ \\
2009 & $3,044,107$ & $3,702,819$ & $82.2 \%$ \\
2010 & $3,386,970$ & $4,045,419$ & $83.7 \%$ \\
\hline & & & *dalam jutaan rupiah
\end{tabular}

Berdasarkan perhitungan yang telah dilakukan, dapat diketahui dari Tabel 18 bahwa tingkat pengembalian atas ekuitas PT. Unilever Indonesia, Tbk. dari tahun 2006 hingga tahun 2010 mengalami peningkatan. Peningkatan ROE PT. Unilever Indonesia, Tbk. terjadi karena peningkatan laba bersih lebih besar daripada peningkatan ekuitas perusahaan. Hal ini menunjukkan bahwa posisi pemilik perusahaan semakin kuat karena adanya keefektifan dalam penggunaan ekuitas untuk memperoleh laba bersih. 


\section{Siklus Konversi Kas}

Siklus konversi kas adalah titik dimana usaha yang dilakukan oleh perusahaan berubah menjadi uang tunai yang dinyatakan dalam jumlah hari. Berikut ini adalah perhitungan siklus konversi kas pada PT. Unilever Indonesia, Tbk tahun 2006-2010:

Siklus Konversi Kas (SKK) = periode konversi persediaan + periode konversi piutang - periode konversi hutang

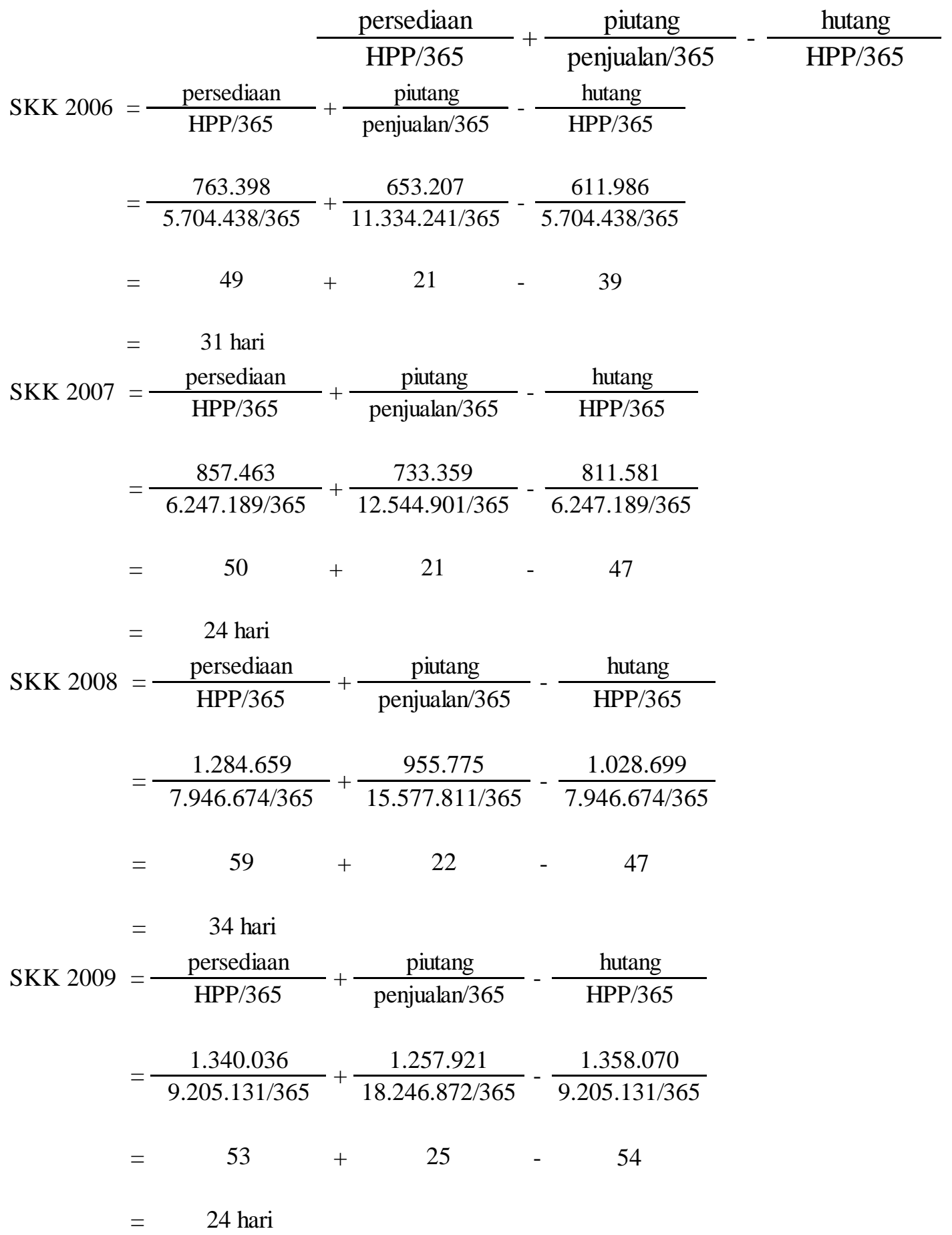




$$
\begin{aligned}
\text { SKK } 2010 & =\frac{\text { persediaan }}{\mathrm{HPP} / 365}+\frac{\text { piutang }}{\text { penjualan/365 }}-\frac{\text { hutang }}{\mathrm{HPP} / 365} \\
& =\frac{1.574 .060}{9.485 .274 / 365}+\frac{1.567 .538}{19.690 .239 / 365}-\frac{1.612 .672}{9.485 .274 / 365} \\
& =60+29-62 \\
& =27 \text { hari }
\end{aligned}
$$

Berdasarkan hasil perhitungan diatas diketahui bahwa siklus konversi kas PT. Unilever Indonesia, Tbk dari tahun 2006 ke tahun 2010 memiliki periode yang semakin pendek. Hal ini semakin baik karena semakin cepat PT. Unilever Indonesia, Tbk memperoleh kas kembali dari usaha yang telah dilakukan. Semakin cepat perusahaan memperoleh kas berarti semakin sedikit kas yang digunakan untuk membiayai aktiva dan perusahaan semakin efektif dalam menjalankan perputaran hutang.

\section{Analisis Rasio Produktivitas}

Rasio produktivitas digunakan untuk menghitung efisiensi atas penggunaan sumber daya (input) dalam menghasilkan produk atau jasa (output).

\section{Rasio Produktivitas Parsial}

Rasio ini menunjukkan produktivitas faktor tertentu yang digunakan untuk menghasilkan keluaran. Beberapa faktor yang digunakan untuk analisis ini adalah:

\section{Produktivitas Bahan Baku}

Produktivitas bahan baku $=\frac{\text { Labakator }}{\text { Btaya bahan baku }}$

Tabel 20 Produktivitas Bahan Baku

\begin{tabular}{crrr}
\hline Tahun & Laba Kotor* & Biaya Bahan Baku* & Produktivitas \\
\hline \hline 2006 & $5,630,803$ & $4,725,809$ & 1.19 \\
2007 & $6,297,712$ & $5,428,528$ & 1.16 \\
2008 & $7,631,137$ & $7,150,409$ & 1.07 \\
2009 & $9,041,741$ & $7,993,202$ & 1.13 \\
2010 & $10,204,965$ & $8,121,154$ & 1.26 \\
\hline & & \multicolumn{2}{c}{ *dalam jutaan rupiah }
\end{tabular}

Penurunan produktivitas bahan baku pada tahun 2008 disebabkan oleh inflasi biaya bahan baku dan kemasan yang signifikan. Hal ini didorong oleh harga minyak dunia yang tinggi, yang mencapai puncaknya pada harga $\$ 146$ per barel di bulan Juli. Penurunan produktivitas ini menunjukkan bahwa pada tahun 2008 PT. Unilever Indonesia, Tbk. tidak dapat melakukan efisiensi penggunaan bahan baku. 


\section{Produktivitas Tenaga Kerja}

$$
\text { Produktlvitas tenaga kerja }=\frac{\text { Eaba kotor }}{\text { Btaya tenaga } \text { ker } j a}
$$

Tabel 21 Produktivitas Tenaga Kerja

\begin{tabular}{crrr}
\hline Tahun & Laba Kotor* & Biaya Tenaga Kerja* & Produktivitas \\
\hline \hline 2006 & $5,630,803$ & 176,017 & 31.99 \\
2007 & $6,297,712$ & 233,878 & 26.93 \\
2008 & $7,631,137$ & 258,990 & 29.46 \\
2009 & $9,041,741$ & 273,482 & 33.06 \\
2010 & $10,204,965$ & 311,375 & 32.77 \\
\hline & & \multicolumn{2}{c}{$*$ dalam jutaan rupiah }
\end{tabular}

Nilai produktivitas parsial tenaga kerja untuk tahun 2010 sebesar 32,77 menunjukkan bawa setiap penggunaan input tenaga kerja sebesar Rp 1.000.000,- akan menghasilkan output sebesar Rp 3.277.000,-.

\section{Produktivitas Overhead}

$$
\text { Produktlvitas overhead }=\frac{\text { Laba } \text { kotor }}{\text { Btaya overhead }}
$$

Tabel 22 Produktivitas Overhead

\begin{tabular}{crrr}
\hline Tahun & Laba Kotor* & Biaya Overhead* & Produktivitas \\
\hline \hline 2006 & $5,630,803$ & 433,698 & 12.98 \\
2007 & $6,297,712$ & 505,691 & 12.45 \\
2008 & $7,631,137$ & 505,266 & 15.10 \\
2009 & $9,041,741$ & 739,986 & 12.22 \\
2010 & $10,204,965$ & 880,116 & 11.60 \\
\hline & & \multicolumn{2}{c}{ *dalam jutaan rupiah }
\end{tabular}

Penurunan produktivitas overhead perusahaan disebabkan oleh penggunaan aktiva tetap yang belum maksimal dalam menciptakan output dan penggunaan biaya pabrikasi yang belum dilakukan secara efisien guna memperkecil input yang digunakan.

\section{Rasio Produktivitas Total}

Rasio ini menunjukkan produktivitas dari semua faktor yang digunakan untuk menghasilkan keluaran. Faktor tersebut adalah bahan baku, tenaga kerja, penyusutan aktiva tetap, dan beban pabrikasi.

$$
\text { Produktivitas total }=\frac{\text { Output atau laba kotor }}{\text { Imput atau btaya produkst }}
$$


Tabel 23 Output \& Input PT. Unilever Indonesia, Tbk.

\begin{tabular}{lrrrrr}
\hline & $\mathbf{2 0 0 6}$ & \multicolumn{1}{c}{$\mathbf{2 0 0 7}$} & \multicolumn{1}{c}{$\mathbf{2 0 0 8}$} & \multicolumn{1}{c}{$\mathbf{2 0 0 9}$} & $\mathbf{2 0 1 0}$ \\
\hline \hline Output / laba kotor & $5,630,803$ & $6,297,712$ & $7,631,137$ & $9,041,741$ & $1,024,965$ \\
Bahan baku & $4,725,809$ & $5,428,528$ & $7,150,409$ & $7,993,202$ & $8,121,154$ \\
Tenaga kerja langsung & 176,017 & 233,878 & 258,990 & 273,482 & 311,375 \\
Penyusutan aktiva tetap & 61,762 & 82,956 & 88,456 & 135,342 & 148,867 \\
Beban pabrikasi & 371,936 & 422,735 & 416,810 & 604,644 & 731,249 \\
Input / biaya produksi & $5,335,524$ & $6,168,097$ & $7,914,665$ & $9,006,670$ & $9,312,645$ \\
\hline
\end{tabular}

Penurunan produktivitas total PT. Unilever Indonesia, Tbk. sejak tahun 2007 disebabkan oleh naiknya biaya bahan baku dan kemasan yang karena naiknya harga minyak, bahan kimia, dan komoditas lainnya di semesater kedua. Tahun 2008 ekonomi global semakin mengkhawatirkan karena terjadinya great depression dan tingkat inflasi mencapai angka dua digit dan kenaikan harga minyak dunia yang mencapai puncaknya pada harga \$146 per barel menyebabkan produktivitas PT. Unilever Indonesia, Tbk menurun secara signifikan ke angka 0,96. Great depression tahun 2008 memengaruhi produktivitas PT. Unilever Indonesia, Tbk. dikarenakan sebagian bahan baku yang digunakan untuk proses produksi merupakan bahan baku import dari perusahaan afiliasi seperti Unilever China Ltd., Unilever Australia Ltd., Lipton Ltd. UK, Best Foods Shandong Ltd., dan sebagainya. Pada tahun 2009 harga komoditas dan rupiah mulai menguat dan perusahaan melakukan efisiensi biaya sehingga produktivitas mulai mengalami peningkatan. Pada tahun 2010 saat kondisi ekonomi telah kembali membaik, PT. Unilever Indonesia, Tbk. berhasil meningkatkan pangsa pasar dengan meluncurkan produk-produk baru. Karena faktor tersebut, pada tahun 2010 ini produktivitas perusahaan kembali meningkat ke angka 1,10 .

\section{Produktivitas Modal Kerja}

Pengelolaan modal kerja yang dilakukan secara ketat oleh PT. Unilever Indonesia, Tbk. merupakan salah satu faktor yang mendukung peningkatan produktivitas perusahaan. Berikut ini merupakan perhitungan produktivitas modal kerja perusahaan.

$$
\text { Produktlutas Modal Kerja }=\frac{\text { Laba kotor }}{\text { Aktiva lancar }}
$$

Tabel 24 Produktivitas Modal Kerja PT. Unilever Indonesia, Tbk.

\begin{tabular}{rrrr}
\hline Tahun & Laba kotor* & \multicolumn{1}{c}{ Aktiva lancar* } & Produktivitas \\
\hline \hline 2006 & $5,630,803$ & $2,604,552$ & 2.16 \\
2007 & $6,297,712$ & $2,694,667$ & 2.34 \\
2008 & $7,631,137$ & $3,103,295$ & 2.46 \\
2009 & $9,041,741$ & $3,601,711$ & 2.51 \\
2010 & $10,204,965$ & $3,748,130$ & 2.72 \\
\hline & & & *dalam jutaan rupiah
\end{tabular}

Hal ini menunjukkan bahwa produktivitas modal kerja perusahaan semakin meningkat dari tahun ke tahun (Tabel 24) yang berarti bahwa pengelolaan modal kerja yang dilakukan efektif untuk meningkatkan output perusahaan. Dari hasil analisis dan perhitungan, diketahui bahwa PT. Unilever Indonesia, Tbk. menggunakan kebijakan modal kerja agresif sehingga output perusahaan dapat terus meningkat untuk meningkatkan profit perusahaan. 


\section{SIMPULAN}

Berdasarkan analisis pengelolaan modal kerja pada peningkatan produktivitas yang dilakukan pada PT. Unilever Indonesia, Tbk., maka dapat disimpulkan:

\section{Berdasarkan Analisis Modal Kerja}

Dari analisis yang telah dilakukan dapat disimpulkan bahwa modal kerja yang dimiliki PT. Unilever Indonesia, Tbk. semakin menurun setiap tahun. Penurunan modal kerja disebabkan perusahaan melakukan pengelolaan modal kerja yang lebih ketat. Hal ini terlihat dari jumlah kewajiban lancar yang besar yang digunakan perusahaan untuk meningkatkan usaha mereka. Dari analisis kebutuhan modal kerja juga terlihat bahwa kebutuhan modal kerja PT. Unilever Indonesia, Tbk. mengalami peningkatan dari tahun ke tahun.

\section{Berdasarkan Analisis Laporan Keuangan}

Terdapat tiga rasio yang digunakan dalam analisis rasio likuiditas, yaitu: rasio lancar, rasio cepat dan rasio kas. Berdasarkan perhitungan yang telah dilakukan, PT. Unilever Indonesia, Tbk. memiliki rasio likuiditas yang cukup rendah dan mengalami penurunan dari tahun 2006 sampai tahun 2010. Penurunan rasio tersebut disebabkan meningkatnya kewajiban lancar yang dimiliki PT. Unilever Indonesia, Tbk. untuk meningkatkan usaha. Terdapat enam rasio yang digunakan dalam analisis rasio likuiditas, yaitu: rasio perputaran piutang, rasio rata-rata penagihan piutang, rasio perputaran persediaan, rasio rata-rata perputaran persediaan, rasio perputaran aktiva tetap dan rasio perputaran total aktiva. Berdasarkan perhitungan yang telah dilakukan, rasio aktivitas PT. Unilever Indonesia, Tbk. mengalami penurunan karena waktu rata-rata penagihan piutang dan rata-rata perputaran persediaan semakin lama. Hanya rasio hutang yang digunakan dalam analisis rasio solvabilitas. Berdasarkan perhitungan yang telah dilakukan, rasio hutang PT. Unilever Indonesia, Tbk. mengalami peningkatan setiap tahun. Hal ini disebabkan oleh peningkatan kewajiban lancar yang lebih besar daripada peningkatan aktiva lancar.Terdapat tiga rasio yang digunakan dalam analisis rasio likuiditas, yaitu: margin laba bersih, tingkat pengembalian atas total aktiva, dan tingkat pengembalian atas ekuitas. Berdasarkan perhitungan yang telah dilakukan, rasio profitabilitas PT. Unilever Indonesia, Tbk. dapat dikatakan baik karena profitabilitas perusahaan terus meningkat. Meningkatnya angka penjualan adalah faktor yang menyebabkan rasio profitabilitas PT. Unilever Indonesia, Tbk. semakin mengalami peningkatan.

\section{Berdasarkan Analisis Produktivitas}

Analisis produktivitas pada PT. Unilever Indonesia, Tbk. menggambarkan adanya penurunan dari tahun 2006 hingga 2008 dan mulai meningkat kembali tahun 2009 dan 2010. Penurunan pada tahun 2008 disebabkan oleh naiknya biaya bahan baku yang dipengaruhi oleh kenaikan harga minyak dan bahan kimia. Untuk produktivitas modal kerja, PT. Unilever Indonesia, Tbk. telah melakukan pengelolaan modal kerja secara baik sehingga produktivitas modal kerja perusahaan terus meningkat dari tahun ke tahun. Hal ini menunjukkan bahwa pengelolaan modal kerja yang dilakukan perusahaan efektif untuk meningkatkan output perusahaan.

\section{Berdasarkan Analisis Modal Kerja}

Dari analisis yang telah dilakukan, dapat disimpulkan bahwa modal kerja yang dimiliki PT. Unilever Indonesia, Tbk. semakin menurun setiap tahun. Penurunan modal kerja disebabkan perusahaan melakukan pengelolaan modal kerja yang lebih ketat. Hal ini terlihat dari jumlah kewajiban lancar yang besar yang digunakan perusahaan untuk meningkatkan usaha mereka. Dari analisis kebutuhan modal kerja juga terlihat bahwa kebutuhan modal kerja PT. Unilever Indonesia, Tbk mengalami peningkatan dari tahun ke tahun. 


\section{DAFTAR PUSTAKA}

Chandra, M. (2010). Analisis Atas Kebijakan Modal Kerja PT. Kalbe Farma, Tbk Periode 2006-2008. Tesis S1 Tidak Dipublikasikan, Universitas Bina Nusantara, Jakarta.

Harjito, D. A, Martono. (2011). Manajemen Keuangan. Yogyakarta: Ekonisia.

Kasmir. (2008). Analisis Laporan Keuangan. Jakarta: Rajagrafindo Persada.

Keown, J. A., Martin, J. D., Petty W., Scott Jr D. F. Alih bahasa oleh Widodo, M. P. (2010). Manajemen Keuangan: Prinsip dan Penerapan, Edisi Kesepuluh, Jilid 2. Jakarta: Indeks.

Mulyadi. (2008). Akuntansi Manajemen: Konsep, Manfaat, dan Rekayasa. Jakarta: Salemba Empat.

Munawir, S. (2007). Analisis Laporan Keuangan, edisi 4. Yogyakarta: Liberty.

Musdholifah, T. E. (2009). Analisis Profitabilitas Pada Perusahaan Manufaktur Go Publik yang Menerapkan Kebijakan Modal Kerja Agresif, Moderat, dan Konservatif di Bursa Efek Indonesia. Jurnal Ekonomi \& Manajemen Volume 1 No. 2: 84-93.

Raharjaputra, H. S. (2009). Buku Panduan Praktis Manajemen Keuangan dan Akuntansi untuk Eksekutif Perusahaan. Jakarta: Salemba Empat.

Rodoni, A., Ali, H. (2010). Manajemen Keuangan. Jakarta: Mitra Wacana Media.

Sawir, A. (2005). Analisis Kinerja Keuangan dan Perencanaan Keuangan Perusahaan. Jakarta: Gramedia Pustaka Utama.

Soetrisna, H. R. (2002). Pengukuran Produktivitas. Laboratorium PSK\&E TI-ITB, Bandung.

Subramanyam, K. R., Wild, J. J. Alih bahasa oleh Yanti, D. (2010). Analisis Laporan Keuangan buku 2 (edisi 10). Jakarta: Salemba Empat.

Syamsuddin, L. (2009). Manajemen Keuangan Perusahaan Konsep Aplikasi dalam: Perencanaan, Pengawasan, dan Pengambilan Keputusan. Jakarta: Rajagrafindo Persada.

Unilever. (2012). Unilever Indonesia. http://www.unilever.co.id Diakses tanggal 13 Maret 2012. 